\title{
The clinical significance of $\gamma$-catenin in acute myeloid leukemia
}

This article was published in the following Dove Press journal:

OncoTargets and Therapy

27 June 2016

Number of times this article has been viewed

\author{
Jiadai $X u^{\prime}$ \\ Wei Wu' \\ Wenyi Shen' \\ Peng Liu ${ }^{2}$ \\ 'Department of Hematology, The First \\ Affiliated Hospital of Nanjing Medical \\ University, Nanjing, '2Department of \\ Hematology, Zhongshan Hospital, \\ Fudan University, Shanghai, People's \\ Republic of China
}

\begin{abstract}
Dysregulation of $\gamma$-catenin may function as an oncogenic factor in various malignancies. We investigated $\gamma$-catenin expression in acute myeloid leukemia (AML) and explored its role in the pathogenesis of AML. $\gamma$-Catenin was significantly overexpressed in AML patients compared to healthy donors. The $\gamma$-catenin expression in AML patients with lower white blood cells $\left(<30 \times 10^{9} / \mathrm{L}\right)$ was significantly higher than those with higher white blood cells $\left(\geq 30 \times 10^{9} / \mathrm{L}\right)$. The expression levels of $\gamma$-catenin in AML patients with mutated CEBP $\alpha$ were significantly higher than those with unmutated $C E B P \alpha$. AML patients with lower $\gamma$-catenin levels were more likely to achieve complete remission compared with patients who have higher $\gamma$-catenin levels. In K562 cells, $\gamma$-catenin knockdown suppressed cellular proliferation, while the cellular migration was greatly enhanced. Moreover, knocking down of $\gamma$-catenin enhanced the cytotoxicity of decitabine in K562 cells. Our investigation has indicated a potential role of $\gamma$-catenin in the pathogenesis of AML.
\end{abstract}

Keywords: $\gamma$-catenin, acute myeloid leukemia, AML, decitabine, prognosis, bone marrow, shRNA

\section{Introduction}

Acute myeloid leukemia (AML) consists of a heterogeneous group of diseases. This disease results from abnormal self-renewal and suppressed differentiation of hematopoietic progenitor cells, which leads to replacement of normal marrow elements. ${ }^{1}$ It has been well established that various clinical features, including old age, high white blood cells (WBC) count at diagnosis, and past history of chemotherapy, radiotherapy, or other hematological diseases, are associated with unfavorable treatment outcomes for AML patients. Furthermore, according to the current World Health Organization categorization of AML, cytogenetic and molecular analyses play an important role in prognostic stratification for AML patients. Prognosis of cytogenetically normal AML (CN-AML) that stratified into intermediated-risk group can be further potentiated by molecular abnormalities, ie, CN-AML with NPM1 mutation or isolated CEBP $\alpha$ mutation in the absence of internal tandem duplications of FLT3-ITD implies low risk. Meanwhile, $\mathrm{CN}$ AML with FLT3-ITD mutation in the absence of NPM1 implies high risk. ${ }^{2}$ However, numerous underlying genetic abnormalities as well as unknown prognostic markers of AML remain to be discovered for prospective novel therapeutic strategies for AML.

Both $\beta$-catenin and $\gamma$-catenin belong to the catenin family. $\gamma$-Catenin, also known as plakoglobin, which is a cytoskeletal protein and intracellular signal transduction protein, shares approximately $80 \%$ sequence homology with $\beta$-catenin. ${ }^{3}$ Human $\gamma$-catenin gene is located on q12 of chromosome 17, with a protein molecular weight of $82 \mathrm{kDa} .{ }^{4}$ Abnormal expression of $\gamma$-catenin gene reportedly occurs in a variety
Department of Hematology, Zhongshan Hospital, Fudan University, I80 Fenglin Road, Shanghai 200032, People's Republic of China Tel +86 2l 60267405

Fax +862160267405

Email liupeng9098@I63.com

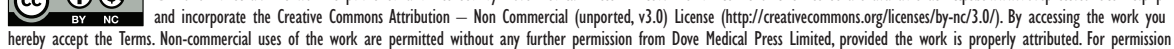
for commercial use of this work, please see paragraphs 4.2 and 5 of our Terms (https://www.dovepress.com/terms.php).
for 
of hematologic malignancies and numerous solid tumors. However, reports on the roles of $\gamma$-catenin in different types of malignancies are varied or even contradictory. Our current study investigated the expression levels of $\gamma$-catenin gene in mononuclear cells in bone marrow (BM) from AML patients. The prognostic significance of $\gamma$-catenin level in de novo AML patients is also discussed. Finally, we explored the function of $\gamma$-catenin in the pathogenesis of AML, with the expectation that $\gamma$-catenin can serve as a potential therapeutic target for AML.

\section{Materials and methods}

\section{Patients and samples}

Between May 2008 and August 2012, BM samples were obtained from 71 patients with primary AML without treatment and 16 healthy donors at the First Affiliated Hospital of Nanjing Medical University. Informed consent were provided by all patients or their legally authorized representatives according to the Declaration of Helsinki for Cryopreservation and Medical Research, and all the methods of this study were approved of by the Institutional Review Board of The First Affiliated Hospital of Nanjing Medical University. A total of 16 healthy Chinese volunteers of Han nationality were recruited, who were unrelated residents in Jiangsu Province, People's Republic of China. All the recruited AML patients were aged between 13 and 85 years (median age: 47 years) and consisted of 40 males and 31 females. Diagnosis of AML was based on the morphologic and cytochemical criteria of the French American British classification. Mononuclear cells were isolated by the Ficoll Hypaque density gradient centrifugation method and stored at $-80^{\circ} \mathrm{C}$ for use. Follow-up data of the patients were provided by the hospital.

\section{Cytogenetic analyses}

Regular cytogenetic analysis was conducted at diagnosis. In accordance with the criteria of the National Comprehensive Cancer Network guidelines of AML (version 1, 2012), all the patients were allocated to three groups according to their cytogenetic risks. Low-risk group: 16 or $\mathrm{t}(16 ; 16), \mathrm{t}(8 ; 21)$, $\mathrm{t}(15 ; 17)$; high-risk group: $-5 / 5 \mathrm{q}-,-7 / 7 \mathrm{q}-, \mathrm{t}(6 ; 9), \mathrm{t}(9 ; 22)$, inv $(3), \mathrm{t}(3 ; 3), 11 \mathrm{q} 23$-non $\mathrm{t}(9 ; 11)$ or complex aberrations ( $\geq$ three independent clonal chromosomal abnormalities); and intermediate-risk group: $+8, \mathrm{t}(9 ; 11)$, normal or other nondefined cytogenetics.

\section{Molecular analyses}

Analyses of FLT3/ITD, NPM1, CEBP $\alpha$, as well as $C$-kit mutations expression, were conducted. ${ }^{5,6}$ Fusion genes,
$A M L 1 / E T O$ and $P M L / R A R \alpha$, were assayed by quantitative reverse transcriptase-polymerase chain reaction.

\section{Quantitative real time-polymerase chain reaction}

The expression of $\gamma$-catenin mRNA was determined by a quantitative RT-PCR. $\beta$-Actin was amplified to normalize the relative levels of $\gamma$-catenin. Total RNA was extracted from stored, frozen mononuclear AML cells using TRIZOL reagent. Moloney Murine Leukemia Virus reverse transcriptase was used to synthesize cDNA from total RNA. Each reaction mixture consisted of $2 \mu \mathrm{L}$ cDNA, $10 \mu \mathrm{L}$ SYBR Green PCR Master Mix, $1 \mu \mathrm{L} \gamma$-catenin primers $(5 \mathrm{nmol} / \mathrm{mL})$ or $1 \mu \mathrm{L} \beta$-actin primers $(5 \mathrm{nmol} / \mathrm{mL})$, and deionized water, making up to a total volume of $20 \mu \mathrm{L}$. The sequences of primers were as follows: 5'-TCGCCATCTTCAAGTCGGG-3' (forward primer) and 5'-AGGGGCACCATCTTTTGCAG-3' (reverse primer) for $\gamma$-catenin; 5'-AAGCCACCCCACTTCTCTCTAA-3' (forward primer) and 5'-AATGCTATCACCTCCCCTGTGT-3' (reverse primer) for $\beta$-actin. The amplification cycling was performed with a denaturation step at $95^{\circ} \mathrm{C}$ for 10 minutes, then 40 cycles at $95^{\circ} \mathrm{C}$ for 30 seconds, $62^{\circ} \mathrm{C}$ for 40 seconds, and $72^{\circ} \mathrm{C}$ for 45 seconds. Experiments were performed in triplicate. The relative expression level was calculated using the $2^{-\Delta \Delta \mathrm{CT}}$ method.

\section{Cell culture}

To investigate whether $\gamma$-catenin was implicated in AML or not, two cell lines were involved: the acute monocytic leukemia line THP-1 and the human erythroleukemia line K562. THP-1 and K562 were cultured in Dulbecco's Modified Eagle's Medium and Roswell Park Memorial Institute-1640 medium, respectively. All culture media (Thermo Fisher Scientific, Waltham, MA, USA) were supplemented with 10\% fetal bovine serum (FBS, Thermo Fisher Scientific). All cells (KeyGEN BioTECH, Nanjing, People's Republic of China) were maintained at $37^{\circ} \mathrm{C}$ in $5 \% \mathrm{CO}_{2} / 95 \% \mathrm{O}_{2}$ environment.

\section{Western blotting}

Western blotting was performed according to widely established protocols. The antibodies were as follows: anti- $\gamma$-catenin (Becton, Dickinson and Company, BD, Oxford, UK), anti-glyceraldehyde-3-phosphate dehydrogenase antibody (Cell Signaling Technology, Danvers, MA, USA), and the secondary horseradish-peroxidase-conjugated antibodies (Zhongshan Golden Bridge Biotechnology Co., Ltd., Beijing, People's Republic of China). 


\section{Establishment of K562/KD}

On the basis of Western blot analysis, $\gamma$-catenin protein was found to be highly expressed in K562 cells in comparison to THP-1 cells. Thereby, K562 was selected for further investigation. The parent cell line K562 was transfected with short hairpin RNA (shRNA) to produce a K562/KD cell model with diminished $\gamma$-catenin expression. To minimize offtarget effects, three types of shRNA plasmids were used for transient transfection into K562 cells (Table 1).

\section{Cell proliferation and migration analysis}

Cell proliferation analysis was conducted with a Cell Counting Kit-8 (CCK-8) kit (Dojindo, Kumamoto, Japan) according to the manufacturer's instructions. After establishing the K562-shRNA model, cells were divided into three groups for further study, including shRNA- $\gamma$-catenin cells (knockdown, K562/KD), shRNA-NC cells (transfection negative control, K562/NC), and normal cells (K562 without transfection, K562/WT). In every group, the cell viability was determined at $0,12,24,36,48$, and 60 hours posttransfection using the CCK-8 reagent. Each assay was run in triplicate and repeated three times.

$$
\begin{aligned}
& \text { Relative cell } \\
& \text { viability (\%) }
\end{aligned}=\frac{\mathrm{OD}_{450} \text { of } \mathrm{K} 562 / \mathrm{KD} \text { or } \mathrm{K} 562 / \mathrm{NC}}{\mathrm{OD}_{450} \text { of } \mathrm{K} 562 / \mathrm{WT}}
$$

Inhibitor rate $=\left(1-\mathrm{OD}_{450}-\frac{\text { Treated }}{\mathrm{OD}_{450}}-\right.$ Untreated $) \times 100 \%$

Cell migration experiment was conducted with the Transwell kit (Becton, Dickinson and Company) according to the instructions of manufacturer.

\section{Statistical analysis}

The definition of complete remission (CR) followed the recommended criteria, ${ }^{7}$ and we defined relapse-free survival (RFS) as the interval from the date of documented $\mathrm{CR}$ until relapse or death in $\mathrm{CR}$ (failure), or alive in $\mathrm{CR}$ at final follow-up (censored). Overall survival (OS) was defined as the interval from the date of initial diagnosis

Table I Three types of shRNA plasmids

\begin{tabular}{ll}
\hline Target site & Target sequence of shRNA \\
\hline JUP-home-1307 & GCTGAAGATTCTGGTGAATCA \\
JUP-home-855 & GTCCTGTTCTATGCCATCACC \\
JUP-homo-I553 & CGCTGTGCGTCTCAACTATGG \\
\hline Abbreviation: shRNA, short hairpin RNA.
\end{tabular}

until death (failure) or alive at final follow-up (censored). Mann-Whitney $U$-test was employed to evaluate quantitative parameters, and $\chi^{2}$ test was used for qualitative parameters. Statistical analyses were performed using Student's $t$-test. The cumulative survival rate was calculated by the KaplanMeier method, and statistical significance was analyzed by the log-rank test. Multivariate Cox proportional hazard model was adopted to explore the prognostic effect of the various clinical variables. A $P$-value less than 0.05 was considered statistically significant, and all reported $P$-values were twosided. All the statistical analyses were performed using the Statistical Program for Social Sciences (SPSS Inc., Chicago, IL, USA; 16.0). Graphs were plotted using GraphPad Prism 5.0 (GraphPad Software, Inc., La Jolla, CA, USA).

\section{Results}

\section{The expression of $\gamma$-catenin in all samples}

An overview of the clinical characteristics of 71 patients is summarized in Table 2. $\gamma$-Catenin gene transcript levels were examined in $\mathrm{BM}$ mononuclear cells from $71 \mathrm{AML}$ patients and 16 healthy individuals by RT-PCR. A statistically significant difference was found in $\gamma$-catenin expression levels between these two groups ( $P=0.020$, Figure 1A). Compared with the healthy donors, AML patients exhibited significantly higher expression levels of $\gamma$-catenin.

\section{Correlation between $\gamma$-catenin expression and clinical characteristics in $A M L$}

We further explored the relationship between $\gamma$-catenin expression and the clinical features as well as known prognostic factors in AML patients. We compared the $\gamma$-catenin expression level among different subtypes (M0-M6) of AML and found significant overexpression in patients with AML-M2 in comparison to the other subtypes $(P=0.053$, Figure 1B). The expression levels of $\gamma$-catenin gene in patients with lower WBC $\left(<30 \times 10^{9} / \mathrm{L}\right)$ were significantly higher than those with higher WBC $\left(\geq 30 \times 10^{9} / \mathrm{L} ; P=0.032\right.$, Figure $1 C)$. In addition, patients with $C E B P \alpha$ mutation had higher $\gamma$-catenin levels compared to those in the unmutated group ( $P=0.047$, Figure 1D). In terms of age, sex, cytogenetics, extramedullary presentation (lymphadenectasis and/or hepatosplenomegaly), mutation status of NPMI and FLT3-ITD, and fusion genes AML1-ETO, no significant correlations with $\gamma$-catenin expression levels (all $P>0.05$, Figure 2A-H) were established. Because of the limited number of samples tested for PML-RAR $\alpha$, we were unable 
Table 2 Patient characteristics

\begin{tabular}{|c|c|c|}
\hline Characteristic & Value & $P_{\text {-value }}{ }^{a}$ \\
\hline Age, years (median, range) & $47(13-85)$ & 0.945 \\
\hline$<60, \mathrm{n}(\%)$ & $50(70.4)$ & \\
\hline$\geq 60, \mathrm{n}(\%)$ & $21(29.6)$ & \\
\hline Sex, n (\%) & & 0.066 \\
\hline Male & $40(56.3)$ & \\
\hline Female & $31(43.7)$ & \\
\hline WBC at diagnosis, $\times 10^{9} / \mathrm{L}$ (median, range) & $20.8(0.7-299.7)$ & 0.032 \\
\hline$<30, \mathrm{n}(\%)$ & $39(56.5)$ & \\
\hline$\geq 30, \mathrm{n}(\%)$ & $30(43.5)$ & \\
\hline Missing data, $\mathrm{n}$ & 2 & \\
\hline $\begin{array}{l}\text { Hemoglobin at diagnosis, g/L (median, } \\
\text { range) }\end{array}$ & $81.0(11.0-159.0)$ & 0.111 \\
\hline Normal (male 120-160, female & II (I7.7) & \\
\hline IIO-I50), n (\%) & & \\
\hline $\begin{array}{l}\text { Anemia (male }<120 \text {, female }<110) \text {, } \\
n(\%)\end{array}$ & $51(82.3)$ & \\
\hline Missing data, $\mathrm{n}$ & 9 & \\
\hline Platelet at diagnosis, $\times 10^{9} / \mathrm{L}$ (median, range) & $40.0(2.0-279.0)$ & 0.284 \\
\hline Normal (100-300), n (\%) & $9(14.3)$ & \\
\hline Thrombocytopenia (<100), n (\%) & $54(85.7)$ & \\
\hline Missing data, $\mathrm{n}$ & 8 & \\
\hline BM blasts at diagnosis, \% (median, range) & $73.6(20.4-99.0)$ & \\
\hline French American British subtype, n (\%) & & 0.292 \\
\hline MO & $2(2.8)$ & \\
\hline MI & $17(23.9)$ & \\
\hline $\mathrm{M} 2$ & $26(36.6)$ & \\
\hline M3 & $9(12.7)$ & \\
\hline M4 & $3(4.2)$ & \\
\hline M5 & $8(11.3)$ & \\
\hline M6 & $5(7.0)$ & \\
\hline Unclassified & I ( $(1.4)$ & \\
\hline FLT3-ITD mutation status, & $5 / 56(8.9)$ & 0.605 \\
\hline \multicolumn{3}{|l|}{ mutated +/total (\%) } \\
\hline NPM I mutation status, mutated +/total (\%) & $\mathrm{I} \mathrm{I} / 52(2 \mathrm{I} .2)$ & 0.831 \\
\hline CEBP $\alpha$ mutation status, mutated $+/$ total $(\%)$ & $13 / 46(28.3)$ & 0.047 \\
\hline Cytogenetics, n (\%) & & 0.114 \\
\hline Favorable & $13(2 \mid .0)$ & \\
\hline Intermediate & $44(70.9)$ & \\
\hline Unfavorable & $5(8.1)$ & \\
\hline Missing data, $\mathrm{n}$ & 9 & \\
\hline Extramedullary presentation, n (\%) & & 0.286 \\
\hline Yes & $19(26.8)$ & \\
\hline No & $52(73.2)$ & \\
\hline
\end{tabular}

Notes: ${ }^{a} \gamma$-Catenin mRNA levels were compared among different groups. MannWhitney $U$-test was employed to evaluate quantitative parameters, and $\chi^{2}$ test was used for qualitative parameters. Statistical analyses were performed using Student's $t$-test. All reported $P$-values were two-sided.

Abbreviations: WBC, white blood cells; BM, bone marrow.

to further explore the relationship between $\gamma$-catenin expression and PML-RAR $\alpha$.

\section{$\gamma$-Catenin expression level in patients achieving CR}

Apart from six patients who received alleviative treatment and nine patients diagnosed as M3, the remaining 56 patients, according to their conditions, received various standard induction regimens, including idarubicin and cytarabine (Ara-C), daunorubicin and cytarabine, mitoxantrone and cytarabine, aclacimomycin and cytarabine, homoharringtonine plus cytarabine and granulocyte-colony stimulating factor (G-CSF), and decitabine combined with half-dose CAG (cytarabine, aclarubicin, G-CSF). Among the 56 patients, 38 achieved CR after one to two therapy cycles. The rate of CR in the group of low $\gamma$-catenin expression was $71.4 \%$, compared with $64.3 \%$ in the high-expression group. Fifty-six patients were divided into $\mathrm{CR}$ group $(\mathrm{n}=38)$ and not $\mathrm{CR}(\mathrm{n}=18)$ group; the $\gamma$-catenin level in $\mathrm{CR}$ group was markedly lower than that in the not-CR group ( $P=0.047$, Figure 3$)$.

\section{Correlations between $\gamma$-catenin expression levels and OS and RFS in AML patients with intermediate-risk cytogenetics}

To identify the clinical prognostic effect of $\gamma$-catenin, we analyzed the prognosis of 56 patients with non-M3 AML. The median follow-up duration for OS was 12.22 months (ranging from 0.07 to 51.17 months). Between patients with high and low $\gamma$-catenin expressions, there was no statistically significant difference in OS and RFS (Figure 4A and B). We further analyzed the prognostic significance of $\gamma$-catenin expression level in subgroups with intermediate-risk cytogenetics, and no difference was revealed in OS and RFS (Figure 4C and D). Moreover, the effects of $\gamma$-catenin on OS and RFS in patients under 60 years of age and with intermediate-risk cytogenetics still remained unknown (Figure 4E and F).

\section{Knockdown of $\gamma$-catenin expression suppressed $\mathrm{K} 562$ viability}

On the basis of Western blot analysis, $\gamma$-catenin protein was highly expressed in K562 cells in comparison to THP-1 cells (Figure 5A). So, K562 was selected for further investigation. The transfection efficiency was determined at 24,48 , and 72 hours posttransfection by fluorescent microscopy (Figure 5B). Consequently, the peak time in transfection efficiency was at 72 hours. The protein expression was further analyzed by Western blotting at 72 hours, showing up to $80 \% \gamma$-catenin knockdown in $\mathrm{K} 562 / \mathrm{KD}$ cells in comparison to $\mathrm{K} 562 / \mathrm{NC}$ cells (Figure 5C). K562/KD cells exhibited significantly lower viability than $\mathrm{K} 562 / \mathrm{NC}$ cells, indicating that the suppression of $\gamma$-catenin expression inhibited cellular viability of K562 cells. Thus, $\gamma$-catenin may be involved in cell proliferation of K562 cells $(P<0.05$, Figure 6A). Moreover, the cell migration experiment was performed in Transwell to compare the migration abilities among K562/ $\mathrm{KD}, \mathrm{K} 562 / \mathrm{NC}$, and $\mathrm{K} 562 / \mathrm{WT}$ cell groups. K562/KD cells exhibited enhanced migration ability over the other two 

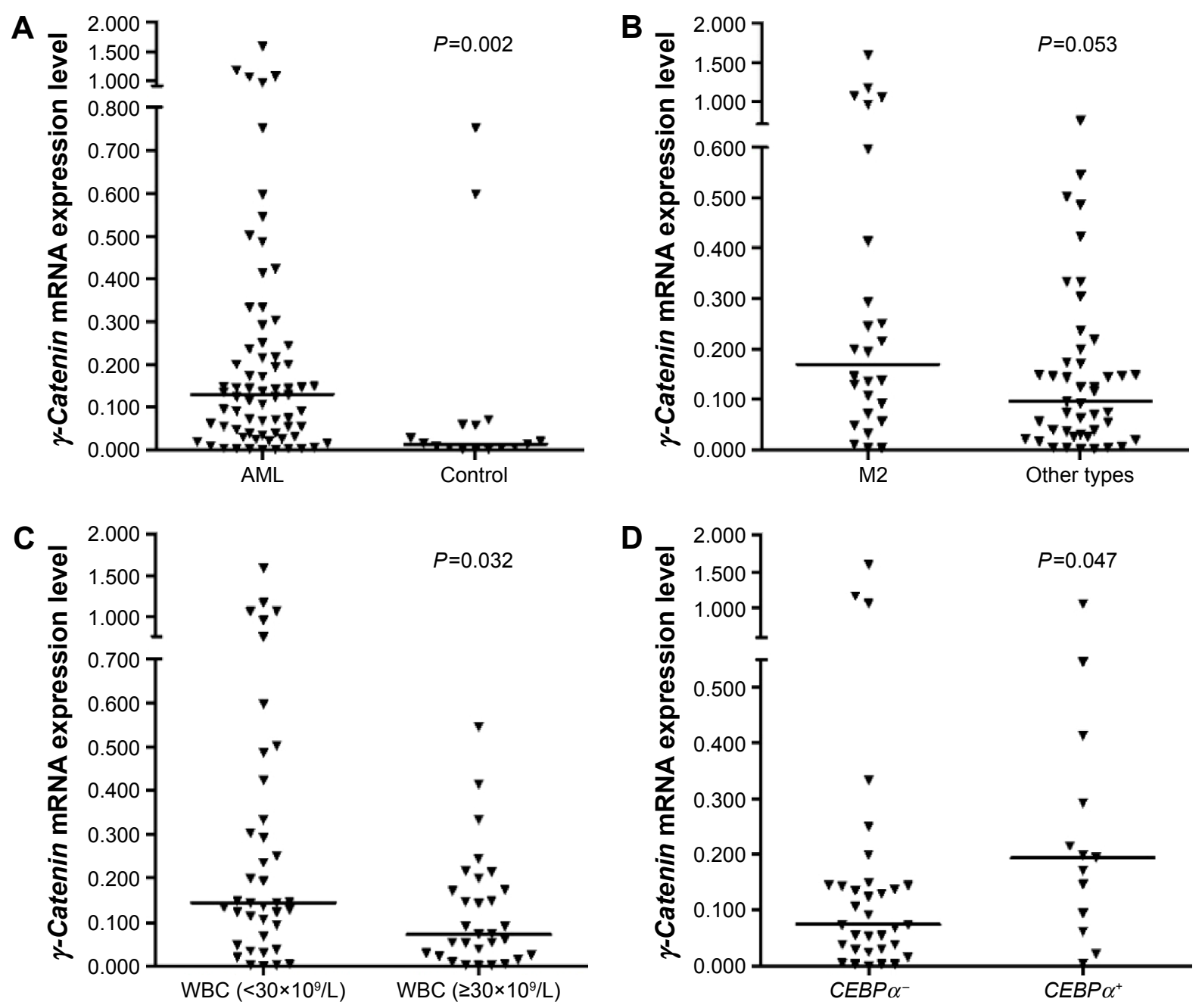

Figure I $\gamma$-Catenin expression and clinical characteristics.

Notes: (A) The level of $\gamma$ catenin gene compared between the 7I AML patients and the 16 healthy controls. (B) The level of $\gamma$ catenin gene compared between patients with AML-M2 and the others. (C) The expression level of $\gamma$ catenin gene in patients with lower WBC $\left(<30 \times 10^{\circ} / \mathrm{L}\right)$ and patients with higher WBC ( $\left.\geq 30 \times 10^{\circ} / \mathrm{L}\right)$. (D) The expression level of $\gamma$ catenin gene in patients with mutated CEBP $\alpha$ gene in contrast with patients with nonmutated CEBP $\alpha$ gene.

Abbreviations: AML, acute myeloid leukemia; mRNA, messenger RNA; WBC, white blood cells.

groups ( $P<0.05$, Figure 6B), indicating that $\gamma$-catenin is a potential inhibitor for K562 cell migration.

\section{Suppression of $\gamma$-catenin expression sensitizes K562 cells to decitabine}

To understand how the knockdown of $\gamma$-catenin affects K562 cells, we treated $\mathrm{K} 562 / \mathrm{KD}, \mathrm{K} 562 / \mathrm{NC}$, and $\mathrm{K} 562 / \mathrm{WT}$ cells with decitabine $(4.4,8.8$, and $17.6 \mu \mathrm{M})$ and examined the inhibitory effects of this agent using CCK- 8 assay kit, and then the inhibitory rate and half maximal inhibitory concentration $\left(\mathrm{IC}_{50}\right)$ were calculated. The results showed that the inhibitory rate of decitabine in $\mathrm{K} 562 / \mathrm{KD}$ cells $\left(\mathrm{IC}_{50}=6.24 \pm 0.77 \mu \mathrm{M}\right)$ was significantly higher than that in $\mathrm{K} 562 / \mathrm{NC}$ cells $\left(\mathrm{IC}_{50}=12.14 \pm 1.38 \mu \mathrm{M}\right)$ or $\mathrm{K} 562 / \mathrm{WT}$ cells $\left(\mathrm{IC}_{50}=22.51 \pm 3.83 \mu \mathrm{M}\right)$, indicating that the downregulation of $\gamma$-catenin could sensitize K562 cells to decitabine $(P<0.05$, Figure $7 \mathrm{~A})$.
Benzyloxycarbonyl-Val-Ala-Asp (zVAD) as a caspase inhibitor can block the apoptotic pathway. Necrostatin-1 (Nec-1) is an inhibitor of programmed necrotic pathway. To investigate the pathway of decitabine-induced cell death, cells were treated separately with 1) growth media, 2) decitabine, 3) zVAD $(20 \mu \mathrm{M})+$ decitabine, and 4) Nec-1 $(30 \mu \mathrm{M})+$ decitabine. From this, we observed that the cytotoxicity of decitabine was inhibited by either zVAD or Nec-1 in any cell group, indicating that decitabine could cause cell death by both apoptotic and programmed necrotic pathways ( ${ }^{*} P=0.001,{ }^{* *} P=0.000,{ }^{* * *} P=0.001,{ }^{*} P=0.000,{ }^{\#} P=0.002$, ${ }^{\#} P=0.000$, Figure 7B). Meanwhile, the cell viability of $\mathrm{K} 562 / \mathrm{KD}$ was significantly lower than that of $\mathrm{K} 562 / \mathrm{NC}$ in the same processing method $(P<0.05)$, indicating once again that the downregulation of $\gamma$-catenin could sensitize K562 cells to decitabine. 

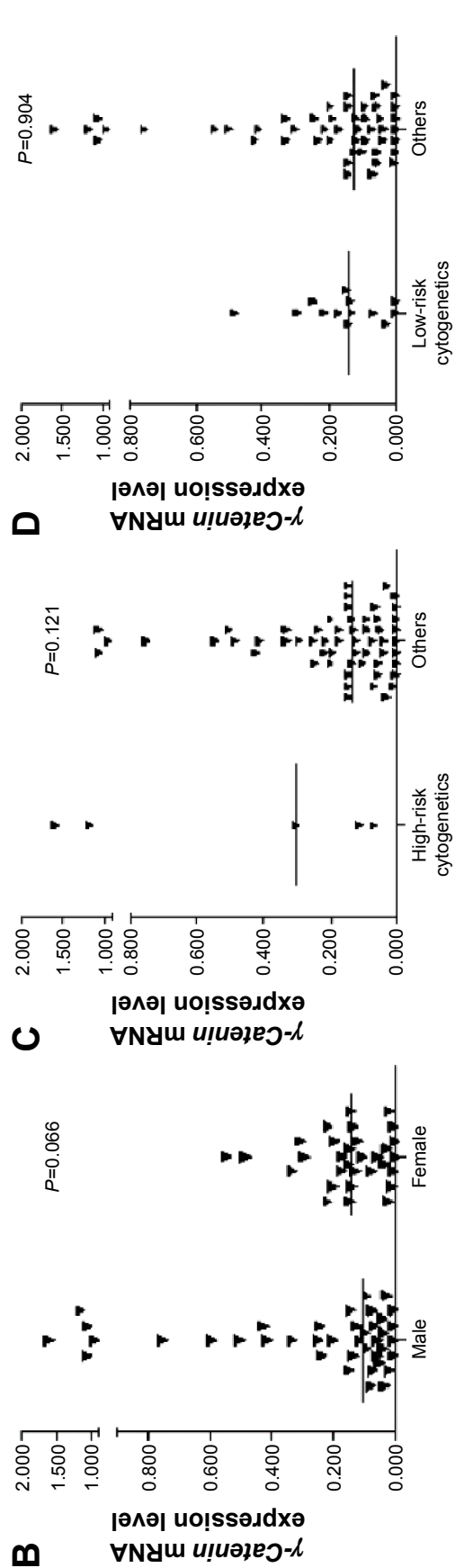

0
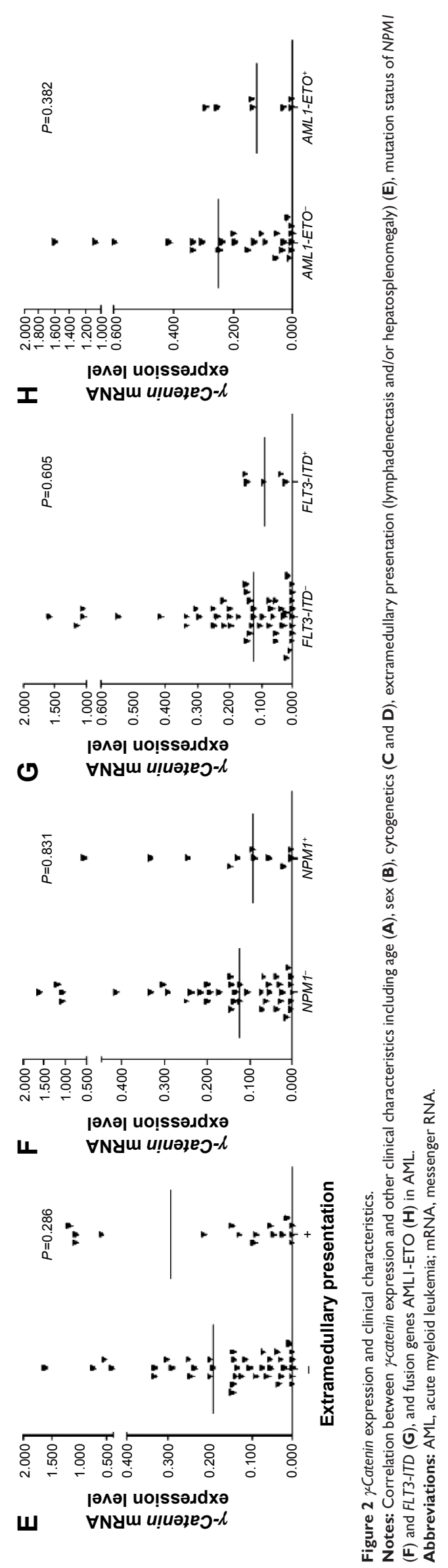


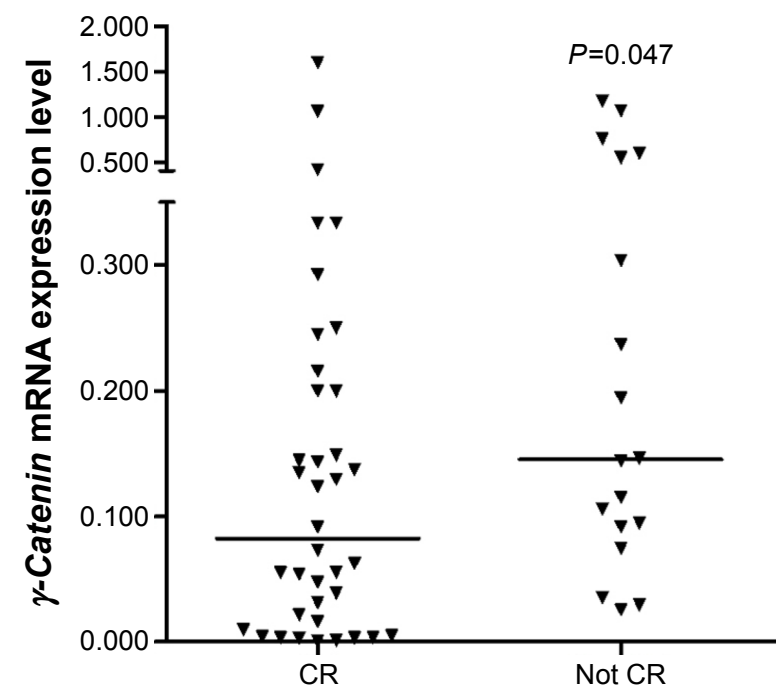

Figure 3 The expression level of $\gamma$-catenin gene compared between patients $(n=38)$ who achieved CR following one to two cycles of standard induction chemotherapy and those who could not achieve CR after two cycles of induction chemotherapy $(n=18)$. Abbreviation: $\mathrm{CR}$, complete remission.

\section{Discussion}

Wnt signaling pathway plays a critical role in the regulation of early embryogenesis and is progressively shut off in differentiated mature cells. ${ }^{8}$ The aberrant activation of Wnt pathway has been found to play a role in the pathological progresses in various malignant diseases, including AML. ${ }^{9} \mathrm{Wnt}$ signaling pathways are generally termed as "canonical" pathways, which are $\beta$-catenin dependent, and "noncanonical" pathways, which are $\beta$-catenin independent. The mechanism of the canonical pathway has been well defined, while the noncanonical one still remains unclear.

Cytoplasmic $\beta$-catenin, the central mediator, is degraded by the APC/Axin-GSK-3 $\beta$ complex. In this complex, APC and GSK-3 $\beta$ 's function is to facilitate the phophorylation of $\beta$-catenin. ${ }^{10}$ In the presence of Wnt signaling, the pathway is initiated via binding of Wnt proteins and the dimeric cell surface receptors composed of frizzled protein (Fzd) and
A

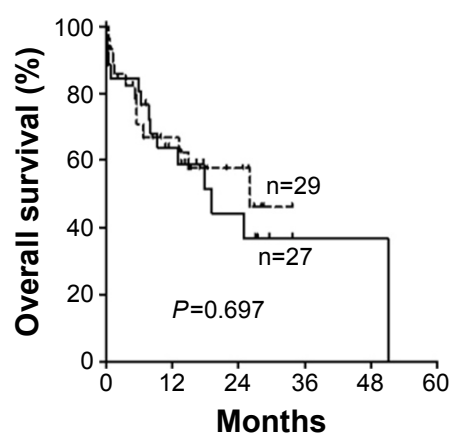

D
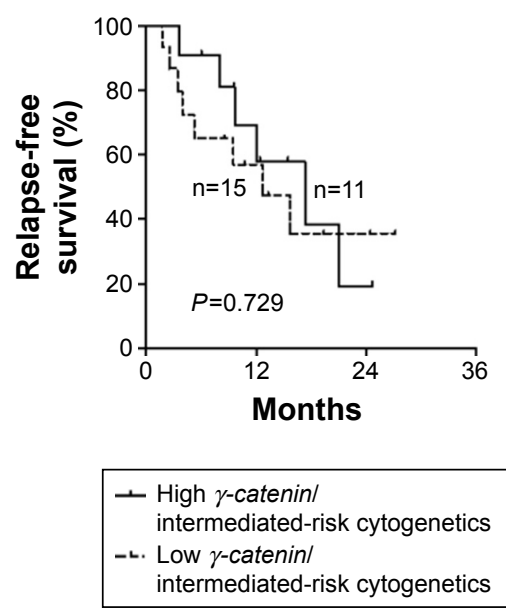

- High $\gamma$-catenin

-ᄂ. Low $\gamma$-catenin
B

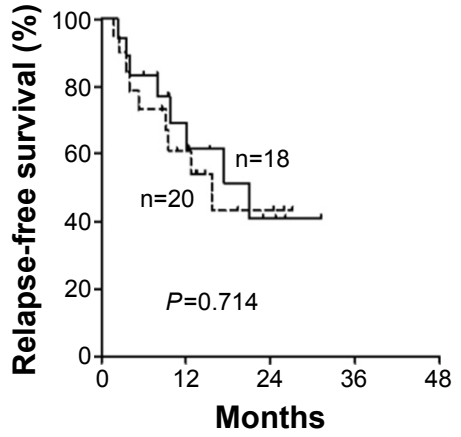

E
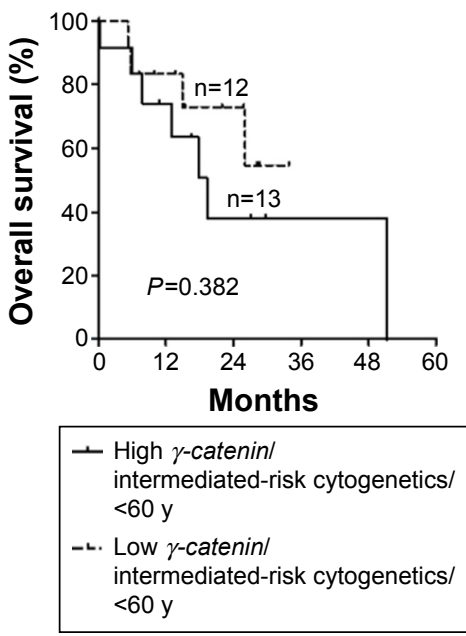
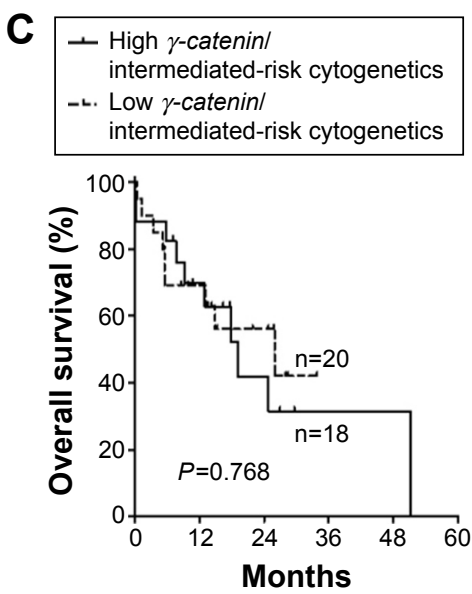

$\mathbf{F}$

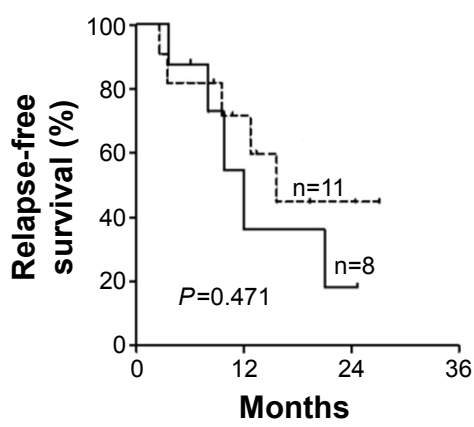

Figure $4 \chi$ Catenin expression and OS and RFS in AML.

Notes: (A and B) Correlations between $\gamma$-catenin expression levels and OS and RFS in AML patients. (C and D) Correlations between $\gamma$-catenin expression levels and OS and RFS in subgroups with intermediated-risk cytogenetics. (E and F) Correlations between $\gamma$-catenin expression levels and OS and RFS in subgroups who were younger than 60 years and with intermediated-risk cytogenetics.

Abbreviations: OS, overall survival; RFS, relapse-free survival; AML, acute myeloid leukemia. 
A

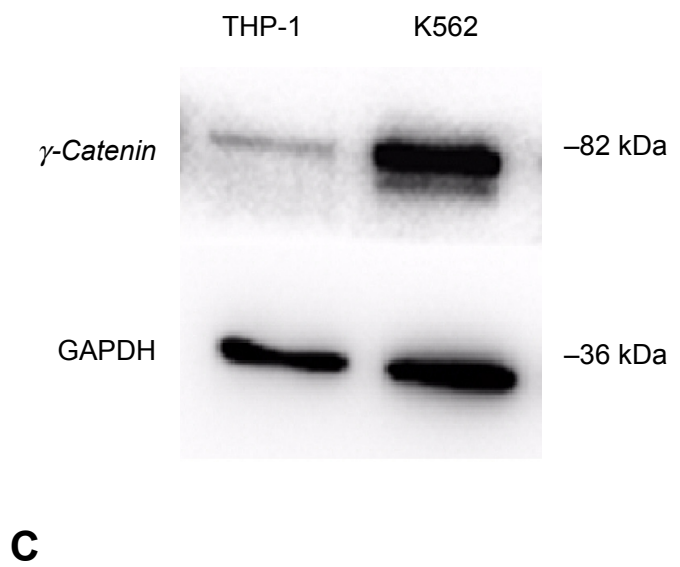

K-Catenin
GAPDH
B
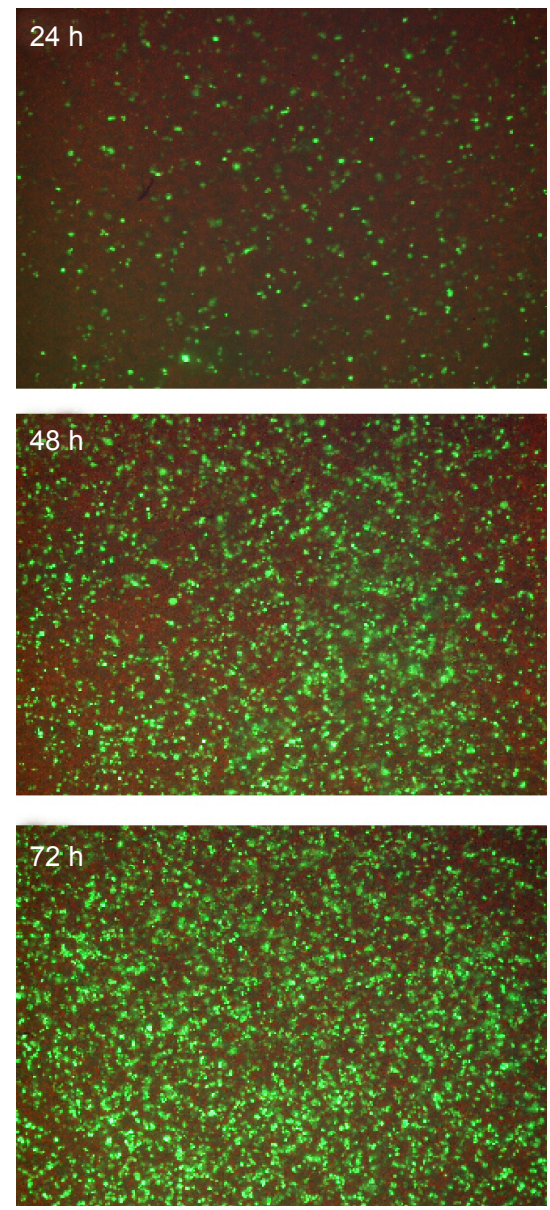

Figure 5 -Catenin protein level in K562 and THP-I cell line and the process of transfection in K562.

Notes: (A) The expression level of $\gamma$-catenin protein was determined by Western blot in K562 cell line and THP-I cell line. (B) The transfection efficiency was determined posttransfection at 24,48 , and 72 hours by fluorescent microscopy $(\times 10)$. (C) shRNA was transfected into K562 cell line to suppress the expression of $\gamma$-catenin protein. Abbreviations: GAPDH, glyceraldehyde 3-phosphate dehydrogenase; KD, knockdown; h, hours; NC, negative control; shRNA, short hairpin RNA.

A

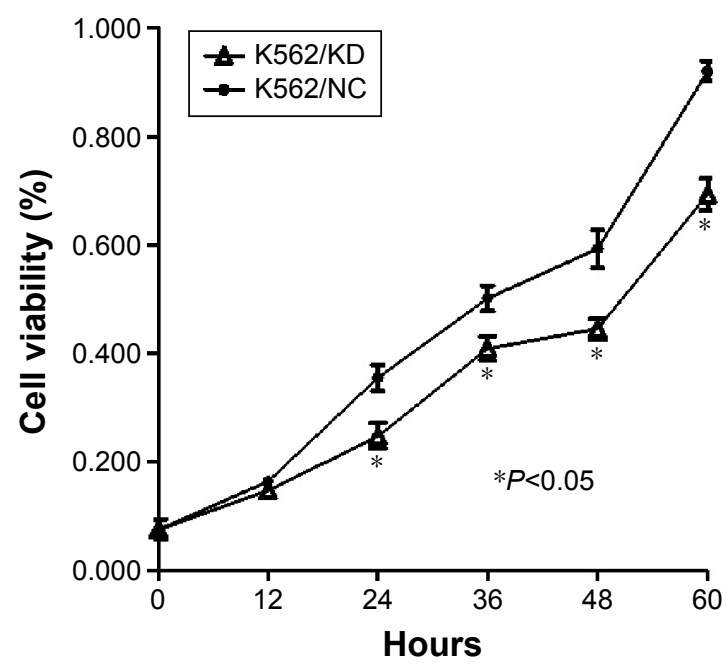

B

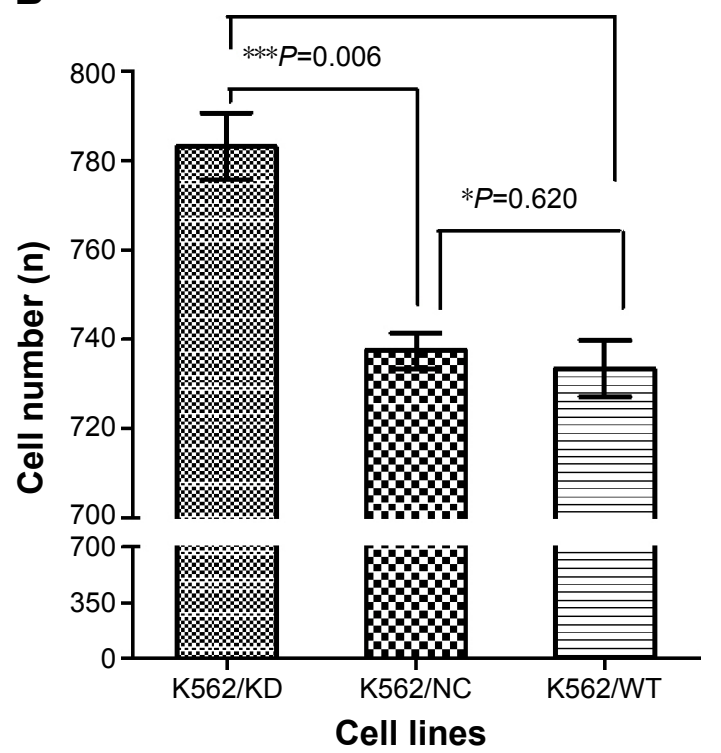

Figure 6 The cell viability and ability of migration.

Notes: (A) The cell viability of K562 cell compared between K562/KD and K562/NC after the suppression of $\mathcal{\gamma}$ catenin protein expression. (B) The ability of migration of K562 cell line after the suppression of $\gamma$-catenin protein expression.

Abbreviations: KD, knockdown; NC, negative control; WT, wild type. 


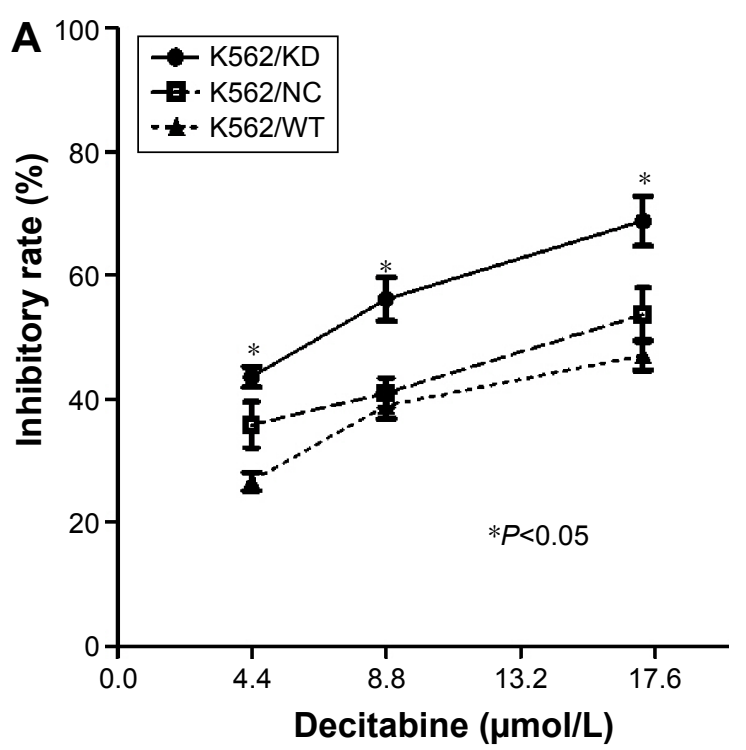

B

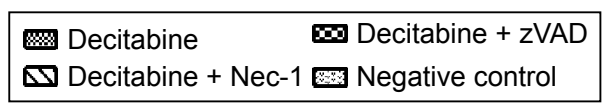

$* P=0.001, * * P=0.000, * * * P=0.001$,

${ }^{\#} P=0.000,{ }^{\#} P=0.002$, and ${ }^{\# \#} P=0.000$

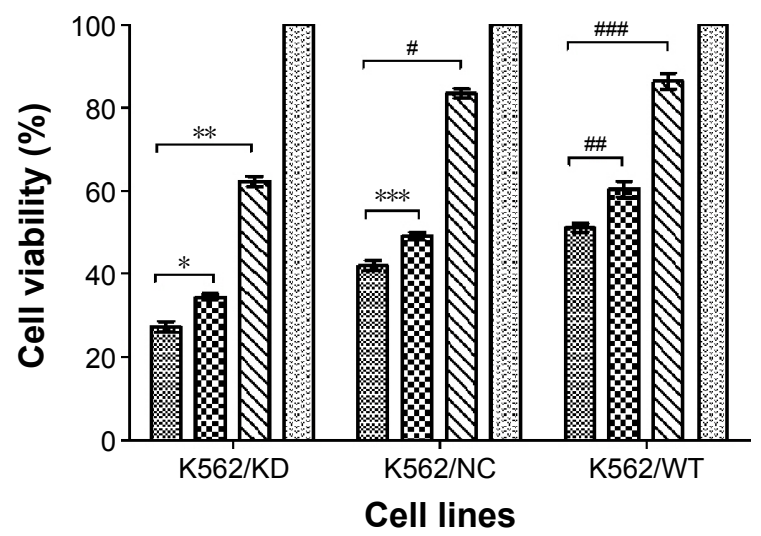

Figure 7 The effect of decitabine.

Notes: (A) The sensitivity of K562 cell line to decitabine therapy after the suppression of $\gamma$-catenin protein expression. (B) The cell viability of K562 cell line after treatment separately with I) growth media, 2) decitabine, 3) zVAD $(20 \mu M)+$ decitabine, and 4) Nec-I (30 $\mu M)+$ decitabine.

Abbreviations: KD, knockdown; Nec-I, Necrostatin-I; NC, negative control; WT, wild type; zVAD, Benzyloxycarbonyl-Val-Ala-Asp.

low-density pipoprotein receptor-related protein 5 or 6 , leading to the recruitment and activation of the disheveled protein. This process turns the low-density pipoprotein receptor-related protein 5 or 6 into phosphorylated form and thereby leads to the dissociation of APC/Axin-GSK-3 $\beta$ complex. As a result, the phosphorylation and degradation of $\beta$-catenin are inhibited. Subsequently, $\beta$-catenin in the dephosphorylated form translocates into the nucleus, where it accumulates and acts as the ultimate effector by binding to TCF/LEF-1 to form a complex and activates the downstream target genes, such as cyclin $\mathrm{D}_{1}$ and $\mathrm{C}$-myc, ${ }^{11-13}$ which are well-established oncogenes, and regulates the cellular proliferation and differentiation. ${ }^{14}$

Several previous studies have reported that in various hematological malignancies, including chronic myelogenous leukemia, ${ }^{15}$ chronic lymphocytic leukemia, ${ }^{16}$ acute lymphoblastic leukemia, ${ }^{17}$ as well as AML, ${ }^{9}$ dysregulation of Wnt signaling has been identified as one of the key roles in leukemogenesis.

$\gamma$-Catenin belongs to the catenin family, which includes $\alpha-, \beta$-, and $\gamma$-catenin. Sharing approximately $80 \%$ sequence homology, $\gamma$-catenin is closely related to $\beta$-catenin. $\beta$-Catenin and $\gamma$-catenin not only play directly an important role in cell-cell adhesion along with transmembranous E-cadherin ${ }^{18}$ but also influence the signal transduction through the Wnt canonical cascade. Unlike the clearly defined oncogenic effect of $\beta$-catenin, the role of $\gamma$-catenin in the aspect of signal transduction remains confusing. There are reports suggesting that $\gamma$-catenin may possess indirect oncogenic activity by blocking the degradation of $\beta$-catenin and in turn increasing the level of $\beta$-catenin in the cytoplasm. ${ }^{19,20}$ Recently, in 2013, Morgan et $\mathrm{al}^{21}$ concluded that $\gamma$-catenin was overexpressed in AML and could promote the stabilization and nuclear localization of $\beta$-catenin. Moreover, it has been reported that in the absence of endogenous $\beta$-catenin expression, $\gamma$-catenin had transcriptional regulatory activity, which is TCF/LEF-family dependent. ${ }^{22}$ Moreover, in 2004, Zheng et $\mathrm{al}^{23}$ reported that the AML-associated translocation products, including PML/RAR, promyelocytic leukemia zinc finger/RAR(X-RAR), and AML-1/ETO, activated the Wnt pathway via upregulating $\gamma$-catenin and in turn encouraged the self-renewal of hematopoietic stem cells and contributed to the leukemogenesis in AML. However, from 2000 to 2006, several groups demonstrated that $\gamma$-catenin acted as a suppressor of tumors and metastasis. Decreased level of $\gamma$-catenin might result in poorer prognosis in several solid tumors, such as bladder, pituitary, oral, skin, and lung cancers. ${ }^{24-28}$

In this study, we compared $\gamma$-catenin mRNA levels in marrow mononuclear cells between naive AML patients and healthy donors, investigated the potential correlation between $\gamma$-catenin and various clinical parameters, and analyzed the clinical significance of $\gamma$-catenin in AML. $\gamma$-Catenin mRNA expression level was significantly higher in AML patients than in healthy donors, which is consistent with previous studies. ${ }^{21,23,29}$ Therefore, elucidating the role of $\gamma$-catenin in AML would help to understand the pathological mechanism of the disease and help develop a potential biomarker for clinical diagnosis and prognosis. Our data further showed that patients who had achieved CR in one to two cycles 
had significantly lower $\gamma$-catenin mRNA expression level in comparison to refractory patients with slow response. So, $\gamma$-catenin mRNA level in naive AML patients might act as an indicator for therapeutic efficacy. Lower level of $\gamma$-catenin suggested better response to chemotherapies. However, in all the 71 AML patients, we did not find any correlation between $\gamma$-catenin expression and OS or RFS. Surprisingly, $\gamma$-catenin mRNA was highly expressed in AML patients with $C E B P \alpha$ mutation or low WBC count at first visit. It is well known that $C E B P \alpha$ mutation indicates better prognosis, while high WBC number at first-visit acts as an adverse prognostic indicator for AML. Thus, further investigation is necessary to better clarify the specific relationship between $\gamma$-catenin and AML development.

Furthermore, we initiated in vitro study with two cell lines: the acute monocytic leukemia line THP-1 and the chronic myeloid leukemia-derived erythroleukemia line $\mathrm{K} 562$. On the basis of Western blot analysis, $\gamma$-catenin protein was highly expressed in K562 in comparison to THP-1, and so K562 was chosen for further investigation. At present, K562 is widely used as one of the model cell lines for hematopoietic study. It has the potential to differentiate into granulocyte, erythrocyte, and megakaryocyte lineages. ${ }^{30}$

Our results showed that downregulation of $\gamma$-catenin reduced the viability and growth rate of K562 cell, which is consistent with the study led by Niu et al. ${ }^{31}$ It has been demonstrated that suppression of $\gamma$-catenin can inhibit the expression of two $\beta$-catenin downstream oncogenes, c-Myc and cyclin $\mathrm{D}_{1}$. As suggested by Morgan et al, ${ }^{21}$ the overexpression of $\gamma$-catenin could stabilize $\beta$-catenin. So we speculate that $\gamma$-catenin could stimulate leukemia cellular growth by affecting $\beta$-catenin in Wnt signal pathway.

We found that downregulation of $\gamma$-catenin enhanced the toxicity of decitabine to K562 cells. Decitabine (5-aza2 -deoxycytidine) is a cytosine analog and a DNA demethylation agent. It can induce leukemia cell differentiation and apoptosis and is the first-line therapeutic agent for AML showing good tolerance. The detailed mechanism of action of decitabine is as yet unclear. However, it was reported in 2007 and 2008 that the cytotoxicity of decitabine may rely on the demethylation of target genes, thus accelerating the expression of tumor suppressor genes. ${ }^{32,33}$ To our knowledge, this is the first study which established that downregulation of $\gamma$-catenin can sensitize K562 cells to decitabine and enhance the drug's activity. The results suggested that $\gamma$-catenin may play a role in the cytotoxicity of decitabtine and may serve as a potential therapeutic target for AML. We also found that the cytotoxicity of decitabine was inhibited by either zVAD or Nec-1. zVAD is a caspase inhibitor, which can block the apoptotic pathway. Nec-1 is an inhibitor of programmed necrotic pathway. This finding indicates that decitabine could cause both apoptosis and programmed necrosis, in accordance to a study by Steinhart et al. ${ }^{34}$

In several solid tumors, $\gamma$-catenin was found to regulate cellular invasion and migration. Mukhina et $\mathrm{al}^{35}$ have found that the downregulation of $\gamma$-catenin increased cell migration and invasion in MCF-7 cells, which express membrane-localized E-cadherin and $\gamma$-catenin. To discern the specific role of $\gamma$-catenin in these processes, the authors reexpressed $\gamma$-catenin in MCF-7 cells, which resulted in decreased migration and invasiveness of MCF-7 cells. The metastasis suppression activity of $\gamma$-catenin has also been described in bladder carcinomas. ${ }^{36}$ In the study by Franke, ${ }^{37}$ different types of classic and new junction proteins/structures were detected in K562 cells, including $\gamma$-catenin in the desmosome junction. These cell-cell junctions are maintained with passages. In our investigation, knockdown of $\gamma$-catenin enhanced K562 cell migration, presumably by weakening intracellular junctions.

\section{Conclusion}

$\gamma$-Catenin gene was significantly overexpressed in AML patients compared with healthy donors. The patients who had lower level of $\gamma$-catenin expression were more likely to achieve $\mathrm{CR}$ in comparison to those with higher $\gamma$-catenin level. $\gamma$-Catenin protein might accelerate the growth of AML cells. Knocking down the $\gamma$-catenin gene could enhance the cytotoxicity of decitabine in K562 cells. However, $\gamma$-catenin seemed to be capable of suppressing the migration of K562 cell line, and this needs further investigation.

\section{Acknowledgments}

This work was supported by the National Natural Science Foundation of China (81170486, 81570123, and 81400079), Jiangsu Province Health Agency Foundation (Z201402), and Jiangsu Province Natural Science Foundation (BK20141028).

\section{Disclosure}

The authors report no conflicts of interest in this work.

\section{References}

1. Estey EH. Acute myeloid leukemia: 2013 update on risk-stratification and management. Am J Hematol. 2013;88(4):318-327.

2. Vardiman JW, Thiele J, Arber DA, et al. The 2008 revision of the World Health Organization (WHO) classification of myeloid neoplasms and acute leukemia: rationale and important changes. Blood. 2009; 114(5):937-951.

3. Aktary Z, Pasdar M. Plakoglobin: role in tumorigenesis and metastasis. Int J Cell Biol. 2012;2012:189521. 
4. Whittock NV, Eady RA, McGrath JA. Genomic organization and amplification of the human plakoglobin gene (JUP). Exp Dermatol. 2000;9(5): 323-326.

5. Fu Y, Zhu H, Wu W, et al. Clinical significance of lymphoid enhancerbinding factor 1 expression in acute myeloid leukemia. Leuk Lymphoma. 2014;55(2):371-377.

6. Qiao C, Zhang R, Hong M, et al. Heterogeneous leukemic clones identified by NPM1 mutation analysis in patient with acute monocytic leukemia. Leuk Lymphoma. 2012;53(5):886-890.

7. Cheson BD, Bennett JM, Kopecky KJ, et al. Revised recommendations of the International Working Group for diagnosis, standardization of response criteria, treatment outcomes, and reporting standards for therapeutic trials in acute myeloid leukemia. J Clin Oncol. 2003; 21(24):4642-4649.

8. Staal FJ, Clevers HC. WNT signalling and haematopoiesis: a WNTWNT situation. Nat Rev Immunol. 2005;5(1):21-30.

9. Lane SW, Wang YJ, Lo Celso C, et al. Differential niche and Wnt requirements during acute myeloid leukemia progression. Blood. 2011; 118(10):2849-2856.

10. McCubrey JA, Steelman LS, Bertrand FE, et al. Multifaceted roles of GSK-3 and Wnt/ $\beta$-catenin in hematopoiesis and leukemogenesis: opportunities for therapeutic intervention. Leukemia. 2014;28(1):15-33.

11. Tetsu O, McCormick F. $\beta$-Catenin regulates expression of cyclin D1 in colon carcinoma cells. Nature. 1999;398(6726):422-426.

12. Behrens J. Control of $\beta$-catenin signaling in tumor development. Ann N Y Acad Sci. 2000;910:21-33; discussion 33-35.

13. van de Wetering $M$, Sancho E, Verweij C, et al. The $\beta$-catenin/TCF-4 complex imposes a crypt progenitor phenotype on colorectal cancer cells. Cell. 2002;111(2):241-250.

14. Polakis P. Wnt signaling in cancer. Cold Spring Harb Perspect Biol. 2012;4(5):a008052.

15. Zhang B, Li M, McDonald T, et al. Microenvironmental protection of CML stem and progenitor cells from tyrosine kinase inhibitors through N-cadherin and Wnt- $\beta$-catenin signaling. Blood. 2013;121(10): 1824-1838.

16. Lu D, Zhao Y, Tawatao R, et al. Activation of the Wnt signaling pathway in chronic lymphocytic leukemia. Proc Natl Acad Sci US A. 2004; 101(9):3118-3123.

17. Yang Y, Mallampati S, Sun B, et al. Wnt pathway contributes to the protection by bone marrow stromal cells of acute lymphoblastic leukemia cells and is a potential therapeutic target. Cancer Lett. 2013; 333(1):9-17.

18. Wijnhoven BP, Dinjens WN, Pignatelli M. E-cadherin-catenin cellcell adhesion complex and human cancer. Br J Surg. 2000;87(8): 992-1005.

19. Li L, Chapman K, Hu X, Wong A, Pasdar M. Modulation of the oncogenic potential of $\beta$-catenin by the subcellular distribution of plakoglobin. Mol Carcinog. 2007;46(10):824-838.

20. Teuliere J, Faraldo MM, Shtutman M, et al. $\beta$-catenin-dependent and -independent effects of $\Delta \mathrm{N}$-plakoglobin on epidermal growth and differentiation. Mol Cell Biol. 2004;24(19):8649-8661

21. Morgan RG, Pearn L, Liddiard K, et al. $\gamma$-Catenin is overexpressed in acute myeloid leukemia and promotes the stabilization and nuclear localization of $\beta$-catenin. Leukemia. 2013;27(2):336-343.
22. Maeda O, Usami N, Kondo M, et al. Plakoglobin ( $\gamma$-catenin) has TCF/ LEF family-dependent transcriptional activity in $\beta$-catenin-deficient cell line. Oncogene. 2004;23(4):964-972.

23. Zheng X, Beissert T, Kukoc-Zivojnov N, et al. $\gamma$-catenin contributes to leukemogenesis induced by AML-associated translocation products by increasing the self-renewal of very primitive progenitor cells. Blood. 2004;103(9):3535-3543.

24. Clairotte A, Lascombe I, Fauconnet S, et al. Expression of E-cadherin and $\alpha-, \beta-, \gamma$-catenins in patients with bladder cancer: identification of $\gamma$-catenin as a new prognostic marker of neoplastic progression in T1 superficial urothelial tumors. Am J Clin Pathol. 2006;125(1): $119-126$.

25. Tziortzioti V, Ruebel KH, Kuroki T, Jin L, Scheithauer BW, Lloyd RV. Analysis of $\beta$-catenin mutations and $\alpha$-, $\beta$-, and $\gamma$-catenin expression in normal and neoplastic human pituitary tissues. Endocr Pathol. 2001;12(2):125-136.

26. Ueda G, Sunakawa H, Nakamori K, et al. Aberrant expression of $\beta$ - and $\gamma$-catenin is an independent prognostic marker in oral squamous cell carcinoma. Int J Oral Maxillofac Surg. 2006;35(4):356-361.

27. Tada H, Hatoko M, Tanaka A, Kuwahara M, Muramatsu T. Expression of desmoglein I and plakoglobin in skin carcinomas. J Cutan Pathol. 2000;27(1):24-29.

28. Bremnes RM, Veve R, Gabrielson E, et al. High-throughput tissue microarray analysis used to evaluate biology and prognostic significance of the E-cadherin pathway in non-small-cell lung cancer. J Clin Oncol. 2002;20(10):2417-2428.

29. Muller-Tidow C, Steffen B, Cauvet T, et al. Translocation products in acute myeloid leukemia activate the Wnt signaling pathway in hematopoietic cells. Mol Cell Biol. 2004;24(7):2890-2904.

30. Lozzio CB, Lozzio BB. Human chronic myelogenous leukemia cell-line with positive Philadelphia chromosome. Blood. 1975;45(3):321-334.

31. Niu CC, Zhao C, Yang ZD, et al. Downregulation of $\gamma$-catenin inhibits CML cell growth and potentiates the response of CML cells to imatinib through $\beta$-catenin inhibition. Int J Mol Med. 2013;31(2):453-458.

32. Ashkenazi A. Targeting the extrinsic apoptosis pathway in cancer. Cytokine Growth Factor Rev. 2008;19(3-4):325-331.

33. Kroemer G, Galluzzi L, Brenner C. Mitochondrial membrane permeabilization in cell death. Physiol Rev. 2007;87(1):99-163.

34. Steinhart L, Belz K, Fulda S. Smac mimetic and demethylating agents synergistically trigger cell death in acute myeloid leukemia cells and overcome apoptosis resistance by inducing necroptosis. Cell Death Dis. 2013;4:e802.

35. Mukhina S, Mertani HC, Guo K, Lee KO, Gluckman PD, Lobie PE. Phenotypic conversion of human mammary carcinoma cells by autocrine human growth hormone. Proc Natl Acad Sci US A. 2004;101(42): 15166-15171.

36. Rieger-Christ KM, Ng L, Hanley RS, et al. Restoration of plakoglobin expression in bladder carcinoma cell lines suppresses cell migration and tumorigenic potential. Br J Cancer. 2005;92(12):2153-2159.

37. Franke WW, Rickelt S. Mesenchymal-epithelial transitions: spontaneous and cumulative syntheses of epithelial marker molecules and their assemblies to novel cell junctions connecting human hematopoietic tumor cells to carcinomatoid tissue structures. Int J Cancer. 2011; 129(11):2588-2599.
OncoTargets and Therapy

\section{Publish your work in this journal}

OncoTargets and Therapy is an international, peer-reviewed, open access journal focusing on the pathological basis of all cancers, potential targets for therapy and treatment protocols employed to improve the management of cancer patients. The journal also focuses on the impact of management programs and new therapeutic agents and protocols on

\section{Dovepress}

patient perspectives such as quality of life, adherence and satisfaction. The manuscript management system is completely online and includes a very quick and fair peer-review system, which is all easy to use. Visit http://www.dovepress.com/testimonials.php to read real quotes from published authors. 